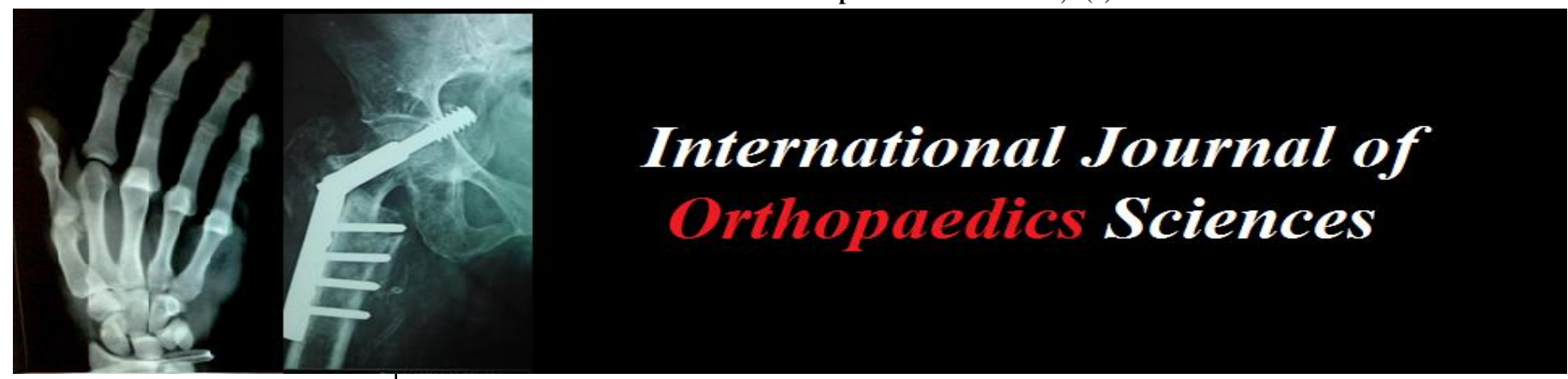

E-ISSN: 2395-1958

P-ISSN: 2706-6630

IJOS 2020; 6(2): 622-623

(C) 2020 IJOS

www.orthopaper.com

Received: 25-02-2020

Accepted: 27-03-2020

Dr. Farooq lone

MS Ortho. Post PG Resident

Orthopaedics GMC Srinagar,

Jammu and Kashmir, India

Dr. Nadeem Ali

MS Ortho. Lecturer

orthopaedics. GMC Srinagar,

Jammu and Kashmir, India

Dr. GN Dar

MS Ortho. Asst. Professor

Orthopaedics GMC Srinagar

Jammu and Kashmir, India

Corresponding Author:

Dr. Farooq lone

MS Ortho. Post PG Resident

Orthopaedics GMC Srinagar,

Jammu and Kashmir, India

\section{Vitamin d status, associated occupational factors and the response to vitamin $d$ therapy at 3 month followup: A study based on Kashmiri population presenting with nonspecific musculoskeltal symptoms in a tertiary care centre}

\section{Dr. Farooq lone, Dr. Nadeem Ali and Dr. GN Dar}

DOI: https://doi.org/10.22271/ortho.2020.v6.i2j.2111

\section{Abstract}

Vitamin D also known as sunshine harmone plays a vital role in calcium homeostasis, cell proliferation and differentiation, regulation of immune system and integrity of neuromuscular system. This study was done to know the occupational relationship of vitamin D Levels in patients presenting to our hospital with multiple symptoms and response to vitamin Dsupplement at three month follow up. A total of 938 patients with nonspecific musculoskeltal complaints were included in our interventional study (March2019-january 2020).Housewife females, chair bound office workers and students were the majority of patients with vitamin D deficiency or insufficiency as reported in our study. Sixty four percent $(64 \%)$ patients at the final followup responded to vitamin D treatment.

Keywords: Vitamin D, occupation, deficiency, insufficiency, musculoskeletal

\section{Introduction}

Vitamin D is a major steroid harmone involved in mineral ion homeostasis regulation. The biological effects of vitamin D are mediated by vitamin D receptors, found in most tissues thus potentially expanding vitamin D actions on nearly all cell systems and organs. A major source of vitamin D is it's synthesis in the skin up on ultraviolet B exposure. Except for fish, food (unless fortified) contains only limited amount of vitamin D. Regardless of the cause clinical manifestations of vitamin D deficiency are largely a consequence of impaired intestinal calcium absorption. A systematic review of 71 studies from across the globe showed that occupation is a major Factor contributing to sub-optimal vitamin D levels, and indoor workers are at a greater risk compared to outdoor workers; more than three-fourths $(78 \%)$ of indoor workers were found to be vitamin DDeficient compared to less than half (48\%) of outdoor workers . Indoor workers spend a significant amount of time working indoors without sunshine exposure. Furthermore, due to the conventional Working time of indoor workers, they are exposed to sunlight mostly during mornings and evenings, the intensity of UV-B exposure is relatively low. Sunlight deprivation among indoor worker sputs them at high risk of developing vitamin D deficiency and its associated health risks. Our study assesed vitamin D levels in 938 patients with different occupations and presenting symptoms and grouped them as vitamin D deficient or vitamin D insufficient.527 out of 938 patients had vitamin D levels less than $30 \mathrm{ng} / \mathrm{ml}$, they received vitamin D supplement for three months and were assesed at 3 month follow up.

\section{Materials and methods}

This study was conducted at Bone and joint surgery hospital Srinagar an associated hospital of Government medical college srinager from March 2019 to January 2020.

All the patients who presented with nonspecific musculoskeletal symptoms were included in the study. Their occupation was properly documented and the blood samples were taken for vit. D level assessment after proper consent. Patients with vitamin D levels less than $30 \mathrm{ng} / \mathrm{ml}$ 
were classified as insufficient level and vitamin D levels less than $20 \mathrm{ng} / \mathrm{ml}$ were classified as deficient level. Patients with levels $<30 \mathrm{ng} / \mathrm{ml}$ received vitamin D supplement and response was assesed at three month followup. Patients with lower than normal levels of vitamin $\mathrm{D}$ received oral administration of $50,000 \mathrm{IU} /$ week for 8 weeks and were assesed at three months with advices to follow the maintenance doses.

Screening test used: serum $25(\mathrm{OH})$ D levels.

\section{Aims and Objectives}

- To find the prevalence of vitamin- D deficiency in patients coming to Orthopaedic OPD with nonspecific musculoskeletal complaints and their occupational relationship.

- To evaluate the effect of vitamin D supplementation in relieving such symptoms.

\section{Observations and Results}

Total number of patients: 938 .

Males: $340(36.2 \%)$

Females: 598 (63.8\%)

Age range (20-60) with mean age 46.3 years.

\section{Occupational status}

Housewife... 540

Household and internal labourer...300

Shopkeeper and office workers (chair bound, clerk, sweeper) ....... 34

Student......................... 44

Teacher........................................... 10

Business (field) .................... 10

\section{Clinical presentation}

Polyarthrialgias................... 300

Nonspecific lower back pain........270

Neck and periscapular pain......... 150

Thigh or calf pain.............. 72

Pain knee and /or ankle.............. 50

Rib pain and discomfort............. 46

Elbow and forearm pain.............. 32

Fatigue and muscle cramps........... 18

In all 938 patients with nonspecific musculoskeletal symptoms, vitamin D levels were assesed.

Out of 938 patients 527 patients had vitamin D levels less than $30 \mathrm{ng} / \mathrm{ml}$. Levels between $20-30 \mathrm{ng} / \mathrm{ml}$ were classified insufficient and those below $20 \mathrm{ng} / \mathrm{ml}$ as deficient.

Insufficient levels in: 210

Deficient levels in: 317

Out of 527 patients with low vitamin D levels the occupational status was:

Housewife....... 330

Household labourer, mine worker, internal workers....... 152

Students. ........ .30

Business.........6 6

Teacher........... 4

Thus most of the patients with nonspecific musculoskeletal symptoms and documented vitamin D low levels were the house hold workers, office workers, underground workers with inadequate exposure to sunlight.

All the 527 patients were put on vitamin D supplements for 8 weeks and followed after three months and assesed for regression of symptoms.

273 patients lost to follow up and the final follow up was done for 244 patients.

Out of 244 at final follow up, 168 (108 deficient and 60 insufficient) patients responded to vitamin D therapy and 76 showed persistent symptoms with no response to vitamin D therapy. Amoung168 patients who responded to vit. D, 152 had vit. D levels in normal range at the final follow up, and 16 still had insufficient levels.

\section{Conclusion}

Patients reporting with nonspecific musculoskeletal complaints and then documented lower levels of vitamin D are mostly the house hold workers, housewives, chair bound employees with inadequate exposure to sunlight.

168 out of $244\{64 \%\}$ patients at the final follow up responded well. Patients with non specific musculoskeletal symptoms reporting to out patient department should be subjected to serum vitamin D level estimation and if levels on lower side should be supplemented with vitamin D as it is observed that there is improvement of symptoms in patients with vitamin D supplementation for a period of eight weeks.

\section{References}

1. Yilmaz R, Salli A, Cingoz HT et al. Efficacy of vitamin $\mathrm{D}$ replacement therapy in patients with chronic non specificic widespread musculoskeletal pain with vitamin D deficiency. Int J Rheum Dis. 2016; 19:1255-62 2.

2. Marie France Le Goaziou, Nadir Kellou, Marie Flori, Corinne Perdrix, Christian Dupraz, Edwige Bodier et al. Vitamin D supplementation for diffuse musculoskeletal pain: Results of a before-and-after study, The European Journal of General Practice. 2014; 20(1):3-9, DOI:10.3109/13814788.2013.825769

3. Christakos S, Dhawan P, Liu Y, Peng X, Porta A. New insights into the mechanisms of vitamin D action. J Cell Biochem. 2003; 88(4):695-705. Doi: 10.1002/jcb.10423. [PubMed]

4. .Holick MF. Vitamin D deficiency. N Engl J Med. 2007; 357(3):266-281. Doi: 10.1056/NEJMra070553. [PubMed].

5. Grober U, Spitz J, Reichrath J, Kisters K, Holick MF. Vitamin D: Update 2013: From rickets prophylaxis to general preventive healthcare. Dermatoendocrinol. 2013; 5(3):331-347. Doi: 10.4161/derm.26738. [PMC free article] [PubMed].

6. Straube S, Andrew Moore R, Derry S, McQuay HJ. Vitamin D and chronic pain. Pain. 2009; 141(1, 2):10-13. Doi: 10.1016/j.pain.2008.11.010. [PubMed].

7. Adams JS, Hewison M. Update in vitamin D. J Clin Endocrinol Metab. 2010; 95(2):471-478. Doi: 10.1210/jc.2009-1773. [PMC free article] [PubMed] [CrossRef]

8. Fuleihan G, Bouillon R, Clarke B, Chakhtoura M, Cooper C, McClung M et al. Serum 25-hydroxyvitamin D levels: variability, knowledge gaps, and the concept of a desirable range. J Bone Miner Res. 2015; 30(7):111933. [PubMed]

9. Awada Z, Ossaily S, Zgheib N. The nutrigenetics and pharmacogenetics of vitamin $\mathrm{D}$ pathways. Curr Pharmacogenomics Person Med. 2014; 12(2):89-103. Doi: $10.2174 / 1875692112666140529002223$. 